\title{
Nulidades en el proceso y en el laudo arbitral
}

\author{
Rómulo García Sosa
}

\begin{abstract}
Sumario
1. Introducción. 2. Convenio Arbitral. 3. ¿Es posible convenir arbitraje, en medio de un juicio seguido ante la Justicia Ordinaria? 4. La decisión sobre la competencia del Tribunal, ¿Podrá ser revisada por el mismo Tribunal arbitral, después de que la asumió? 5. Acción de Nulidad del Laudo Arbitral 6. ¿Procede aplicar otras causales de nulidad, como las que establece el artículo 355 del CPC? 7. ¿Por qué interviene el Estado, a través de las Cortes Provinciales, como contralor legal de los laudos arbitrales? 8. ¿Cabe el recurso de casación de la sentencia que emita la Corte Provincial respecto de la acción de nulidad de laudo arbitral?
\end{abstract}

\section{INTRODUCCIÓN}

La Ley de Arbitraje y Mediación es relativamente nueva, rigió inicialmente a partir de su publicación en el Registro Oficial del 4 de octubre de 1997', tras un importante esfuerzo por expedirla. Fue codificada luego en el 2006, la cual rige actualmente. No obstante, aún hay inconvenientes o reparos en su aplicación, por eso es importante analizar los casos de nulidad del laudo arbitral.

1. Registro Oficial No. 145. Reformado mediante Codificación 2006-014 publicada en cl R.O. No. 17 de 14 de diciembre del 2006. 
La Constitución de la República reconoce en su artículo 190, al arbitraje como uno de los procedimientos alternativos para la solución de conflictos, que“...se aplicarán con sujeción a la ley,en materins en las que por su naturaleza se pueda transigir...." El artículo 1 de la Ley de Arbitraje y Mediación preceptúa que "El sistema arbitral, es un mecanismo alternativo de solución de conflictos al cual las partes pueden someter de mutuo acuerdo, expresamente y por escrito, sus controversias susceptibles de transacción, existentes o futuras, para que sean tratadas por los Tribunales de arbitraje administrado o por árbitros independientes que se conformaren para conocer dichas controversins."

La condición constitucional y legal para que proceda el arbitraje es, consecuentemente, la de que exista expresamente y por escrito, un acuerdo mutuo y previo entre dos partes para solucionar sus controversias actuales o futuras, y de que éstas sean susceptibles de transacción.

\section{Convenio arbitral}

En general, los convenios o contratos deben reunir los requisitos que impone la ley, para su existencia, o para su validez.El artículo 1453 del Código Civil prescribe que: "Las obligaciones nacen, ya del concurso real de las voluntades de dos o más personas, como en los contratos o convenciones;...". El arbitraje no nace de la ley, ni de normas generales o actos administrativos, ni de la voluntad unilateral de una parte, como el testamento o la donación.

El artículo 1454 del mismo Código prescribe que: "Contrato o convención es un acto por el cual una parte se obliga para con otra a dar, hacer o no hacer alguna cosa. Cada parte puede ser una o muchas personas." Nuestra legislación no hace diferencia entre convenio y contrato, no obstante que se sostiene en la doctrina y prevén legislaciones como la francesa, que el primero es la especie y el segundo el género. ${ }^{2}$

2. Ramón Sínchez Medal: "De los contratos Civiles". 
Lo importante es que el contrato o convenio es la fuente de Derechos y obligaciones, que permite a las partes expresar su voluntad libre de dar, hacer o no hacer algo, de manera que sean exigibles entre ellas las obligaciones recíprocas estipuladas, bajo el principio de pacta sunt servanda que recoge el artículo 1561 del Código Civil: "Todo contrato legalmente celebrado es una ley para los contratantes, y no puede ser invalidado sino por su consentimiento mutuo o por causas legales." De ahí que la interpretación de la voluntad de las partes contractuales solo procede en los términos del Título XIII del Libro IV del Código Civil, y de puntuales normas exorbitantes de aquellas, pertenecientes al campo administrativo. Al juez o al árbitro no le corresponde modificar la voluntad de las partes, sino aplicar los principios del Derecho a los hechos motivo de la controversia generada en la ejecución de ese contrato o convenio.

Los contratos existen, cuando entre las partes se ha dado la expresión de su voluntad libre de producir o transferir Derechos u obligaciones. Los elementos para que una persona pueda obligarse con otra por acto o declaración de voluntad son, capacidad, consentimiento, objeto lícito, causa lícita ${ }^{3}$ a lo que debemos añadir, para el caso del Estado, la competencia del funcionario que interviene a nombre del Estado, y desde luego el cumplimiento de las solemnidades previstas por la ley para cada especie de contrato, como el contrato de compraventa o de promesa de compraventa de un inmueble, que debe ser elevado a escritura pública.

Cuando tales actos o declaraciones están afectados de un vicio previsto por la ley, no existe el convenio o contrato, comocuando una parte o ambas carecen de capacidad; si vio afectado su consentimiento, carece el acto de causa y objeto lícitos, o cuando no cumplen las formalidades establecidas en la ley. No es suficiente, entonces, que se invoque irrestrictamente la libertad de contratar que garantiza el artículo 66 numeral 16 de la Consti-

3. Art. 1461 Código Civil: "Para que uma persona se obligue a otra por un acto o declaración de voluntad es necesariv: - "lo. - Que sea legalmente capaz; - "2o.- Que consienta en dicho acto o declaración. y su consentimiento no adolezca de vicio: - "3o, - Que recaiga sobre un objeto licito; y: - "\$o.- Que tenga una causa licita. - "La capacidad legal de una persona consiste en poderse obligar por si misma. y sin el ministerio o la autorizacion de otra." 
tución de la República y el artículo 8 del Código Civil ${ }^{5}$, pues para la existencia y validez de los contratos debe observarse las condiciones, los requisitos y las formalidades previstos por la propia ley.

No obstante ser de todos conocido, es preciso recordar el texto del artículo 5 de la Ley de Arbitraje y Mediación: "El convenio arbitral es el acuerdo escrito en virtud del cual las partes deciden someter a arbitraje todas las controversias o ciertas controversias que hayan surgido o puedan surgir entre ellas respecto de una determinada relación jurídica, contractual o no contractual. - "El convenio arbitral deberá constar por escrito $y$, si se refiere a un negocio juridico al que no se incorpore el convenio en su texto, deberá constar en un documento que exprese el nombre de las partes y la expresión inequívoca del negocio jurídico a que se refiere. En los demás casos, es decir de convenios arbitrales sobre las indemnizaciones civiles por delitos o cuasidelitos, el convenio arbitral deberá referirse a los hechos sobre los que versará el arbitraje..."

El Art. 6 de la misma LAM complementa: "Se entenderá que existe un convenio arbitral no solo cuando el acuerdo figure en un único documento firmado por las partes, sino también cuando resulte de intercambio de cartas o de cualquier otro medio de comunicación escrito que deje constancia documental de la voluntad de las partes de someterse al arbitraje."

Se puede convenir arbitraje, entonces, solamente por acuerdo escrito, de cualquiera de las formas previstas por la ley, que exprese la voluntad de las partes de someter al arbitraje las controversias que hayan surgido o puedan surgir entre ellas, por una relación jurídica, contractual o extracontractual, siempre que sean susceptibles de transacción.

Prescribe el Art. 2348 del Código Civil que: "Transacción es un contrato en que las partes terminan extrajudicialmente un litigio

4. Constitución de la República: "Art. 66.- Se neconoce y garantizarí a las personas: ... "16. El Derecho a la libertad de contratación."

5. Código Civil: "Art. 8.- A nadie puede impedirse la acciỏn que no esté prohibida por la ley." 
pendiente, o precaven un litigio eventual. ..." La transacción es, necesariamente, un contrato bilateral. El mismo artículo sigue que: "No es transacción el acto que sólo consiste en la renuncia de un Derecho que no se disputa." La naturaleza de la transacción, es la terminación entre las partes de un litigio en curso, o evitar uno eventual.

Precaver significa "Prevenir un riesgo, daño o peligro, para guardarse de él y evitarlo." (DRAE).

Es inexistente el convenio arbitral si las partes han acordado someterse al arbitraje respecto de un Derecho o de un objeto no sujeto a transacción; como cuando, según el Código Civil, el objeto es el estado civil de las personas, la condición de hijo, por ejemplo. Sobre Derechos ajenos, o que no existen. O cuando el acuerdo arbitral, está afectado de error, fuerza o dolo. Por la naturaleza de la transacción, tampoco procede pactar arbitraje sobre un litigio entre las partes que hubiera sido previamente sometido por ellas a la justicia ordinaria o que haya terminado con decisión pasada en autoridad de cosa juzgada.

No es admisible un convenio arbitral que no contenga los elementos sustanciales para su existencia, como aquellos en los que aparecen determinadas cláusulas patológicas que, por obscuridad o imprecisión, afectarían a la naturaleza misma del arbitraje e impedirían su ejecución, como cuando se refieren a una ley derogada o, en el caso de arbitraje administrado, a una entidad que no es un Centro Arbitral existente legalmente, pues hay sin duda error sustancial que impide que el arbitraje sea entendido como la expresión de la libre voluntad de las partes, y de que lo hubieran acordado con su pleno conocimiento de someterse a ese trámite, conforme las vigentes normas aplicables al arbitraje.

Entonces, si el convenio arbitral no existe, no produce efecto alguno, el arbitraje no procede y el Tribunal no puede conocer del juicio arbitral y deberá declararse incompetente. 
Las partes pueden renunciar al acuerdo compromisorio. El artículo 8 de la LAM prevé que las partes pueden renunciar de mutuo acuerdo y por escrito (se deshace como se hizo) al convenio arbitral, de manera que así se entienda cuando cualquiera de ellas acuda con su demanda ante los jueces ordinarios, y en cuanto la otra, al contestar la demanda, no oponga la excepción de existencia del convenio arbitral. El juez será entonces competente para conocer y resolver la controversia conforme a las leyes adjetivas comunes.

Si la parte demandada opone la excepción de existencia del convenio arbitral, le corresponde al Juez "...sustanciarla y resolverla corriendo traslado a la otra parte y exigiendo a los litigantes la prueba de sus afirmaciones, dentro de tres días subsiguientes a la fecha en que se haya notificado el traslado. Aceptada la excepción deberá ordenarse el archivo de la causa, en caso contrario, ejecutoriado el auto dictado por el juez, se sustanciará la causa según las reglas generales."

En el evento de que el Juez acepte la excepción y decline su competencia en razón de la existencia del convenio arbitral ${ }^{6}$, deberá proceder como manda el artículo 129, ordinal 9, del Código Orgánico de la Función Judicial" ${ }^{7}$ a homologar el acuerdo de las partes y a ordenar la remisión del proceso al Tribunal competente, es decir, al Centro de Arbitraje convenido por las partes, para que conozca y resuelva la causa el Tribunal Arbitral que se conforme ajustado al convenio, al Reglamento Interno del Centro y a la LAM.

6. Articulo $7 \mathrm{de}$ la LAM: "El convenio arbitral, que obliga a las partes a acatar el laudo que se expida. impide someter el caso a la justicia ordinaria. - "Cuando las partes hayan comenido de mutho actuerlo someter al arhitraje sus controversiats, los jucces deherain inhibirse de conocer cualquier demanda que verse sobre las relaciones juridicas que las hayan originalo, salvo en los casos de excepcion previstos en esta Ley: En caso de duda, el irgano judicial respectivo estari a faror de que las controversias scan resuellas mediante arbirraje. ..."

7. Código Orgánico de la Función Judicial, Art. 129: "FACULTADES Y DEBERES GENÉRICOS DE LAS JUEZAS Y.JUECES. A más de los deheres de toda senidora o servidor judicial, las juezas y jueces. segrin corresponda, tienen las siguientes facultades y debores genéricos: ... "9. En cualquier eszado de la causa, las juczas y jueces que adviertan ser incompetentes para conocer de la misma ... - "Si la incompefencia es en razin de la materia, declarará la mulidad y mandará que se remia cl proceso al Tribunal o jueza o jues competente para que dé inicio al juzgamiento, pero el ticmpo transcurrido entre la citacion con la demanda y la declaratoria de nulidad no se computurain dentro de los plazos o términos de caducidad o prescripción del Derecho o la acción." 


\section{3. ¿ES POSIBLE CONVENIR ARBITRAJE, EN MEDIO DE UN JUICIO SEgUido aNTE la JUSTICIA ORdinaria?}

Si las partes lo deciden de mutuo acuerdo, expresamente y por escrito, bajo las condiciones del artículo 4 de la LAM, es procedente, y el Juez, en consecuencia, deberá declinar su competencia y remitir el proceso al Centro Arbitral o a los árbitros, como hayan convenido por las partes.

Tampoco procede el arbitraje cuando se trata del ejercicio de una potestad pública, como los actos políticos, de poder, de gobierno como de defensa nacional, tributarios, o punitivos de Derecho Público, éstos, en el ejercicio de una ley administrativa o penal. Es decir, cuando el Estado, como tal, ejerce potestades públicas, y se expresa mediante los actos administrativos unilaterales que le atribuye la Constitución y la Ley. Así procede cuando se trata de la prestación de servicios públicos por el propio Estado o mediante delegación a concesionarios, para atender las necesidades colectivas. El trámite será, a tal propósito, el de reclamos, quejas, denuncias y se seguirá el proceso en sede administrativa o judicial, con la presentación de los recursos o las acciones previstos en las leyes administrativas.

Las controversias entre el Estado y sus contratistas que se generan como consecuencia de la ejecución de un contrato administrativo ${ }^{8}$, como las multas convenidas en los contratos con el Estado, que son parte de la naturaleza y de las estipulaciones del contrato en su integridad y de su ejecución, son esencialmentetransigibles y, por ende, sujetas al arbitraje; pues siendo el contrato una entidad, sus cláusulas deben interpretarse unas con otras, dándose a cada una el sentido que mejor convenga al contrato en su totalidad ${ }^{9}$.

8. Articulos $60,113,114$ y 115 de la Ley Orgánica del Sistema Nacional de Contratación Pública.

9. Artículo 1580 del Código Civil: "Las clúusulas de an contrato se interpretarán unas por otras, dandose a cadu una el sentido que mejor comenga al contrato en su totalidad, - "Pedrain tambiein interpretarse por las de otro contrato entre las mismas parkes y sohre la misma materia. - "O por la aplicacion practica que hatan hecho de cllas ambas partes, o una de las partes con aprohación de la otra" 
Aún más, le corresponde al árbitro o Tribunal, de ser el caso, mesurar el exceso en la aplicación de multas ${ }^{10}$ cuando hubieran sido impuestas en exceso de los límites previstos por la Ley Contractual y el contrato, para lo cual la propia ley manda que el contratante debe optar por otras acciones, que no la imposición de multas por encima de esos límites, la ejecución de las garantías del cinco por ciento del valor del contrato por fiel cumplimiento, por ejemplo ${ }^{11}$; o su terminación unilateral y anticipada en los casos de incumplimiento de contratista, es previamente a cumplir las condiciones exigidas por la ley ${ }^{12}$.

La nulidad, por su parte, es la sanción legal establecida para la omisión de los requisitos y formalidades que la ley prevé para la validez de los actos jurídicos, o de los procesos, que debe ser declarada por el juzgador.

Cuando el convenio arbitral se ha celebrado con prescindencia de una de las condiciones para su validez, es nulo. ${ }^{13}$

Respecto del Estado, la norma constitucional prevé que: "En Ia contratación pública procederá el arbitraje en Derecho, previo pronunciamiento favorable de la Procuraduria General del Estado, conforme a las condiciones establecidas en la ley."

Si bien no procede el arbitraje para los actos administrativos, queda en claro que en los contratos en que intervenga el Estado como parte, procede estipular el arbitraje para resolver las controversias que se generen entre las partes como consecuencia de su ejecución e interpretación y que ellas no las hubieren podido solucionar de mutuo acuerdo ${ }^{1+}$. Si no se hubiera pactado arbitraje,

10. Árticulo 1560 del Código Civil, primer inciso: "Cuando por el pacto principal ama de las partes se abliga a pagar una cantidad determinada. como cquiralente a to que por la otru parte debe prestarse, y la pena consiste asimismo en el pago de una cantidad determinada, podrá pedirse que se rehaje de ésta lo que exceda al dupio de aquella; de manera que, ora se cobre sólo la pena. ora la pena juntameente con la obligacion principal, nunca se pague más que esta última doblada...."

11. Articulo 70, último inciso, de la Ley Orgánicn del Sistema Nacional de Contratación Pública.

12. Articulo 9.4 de la Ley Orgánica del Sistema Nacional de Contratación Pública.

13. Artículo 1512.- Los acios o contratos que la Ley declara inválidos, no dejan de serlo por las cláusulas que en ellos se introduzcan y en que se renuncie la acción de nulidad.

14. Articulo 104 de la Ley Orgánica del Sistema Nacional de Contratación Pública y Arts. 162 y 163 del Reglamento General de la misma Ley. 
las controversias de los contratos administrativos y decidan acudir a sede judicial, el procedimiento, en esos casos queda en claro, se tramitará ante el Tribunal Distrital de lo Contencioso Administrativo ${ }^{15}$, conforme a la Ley de la materia y al artículo 38 de la Ley de Modernización, etc.

No hay en la Constitución limitación alguna al respecto, salvo las condiciones que impone, que se tramite el arbitraje en Derecho, y que, previamente, el Procurador General del Estado emita pronunciamiento favorable, pero en los casos previstos en la Ley ${ }^{16}$.

El Código Civil prescribe en su artículo 8, que: "A nadie puede impedirse la acción que no esté prohibida por la ley." Y previene las limitaciones a ese principio: artículo 9: "Los actos que prohibe la ley son nulos y de ninguin valor; salvo en cuanto designe expresamente otro efecto que el de nulidad para el caso de contravención." $\mathrm{Y}$, artículo 10: "En ningún caso puede el juez declarar válido un acto que la ley ordena que sea nulo."

La inexistencia puede alegarse como excepción, no puede ser convalidada ni ratificada por las partes; la nulidad puede alegarse como acción o como excepción y puede ser convalidada por las partes en los casos determinados por la ley ${ }^{17}$.

Recibida una demanda arbitral, el Director del Centro de Arbitraje verificará el cumplimiento de los requisitos formales de la demanda y de la existencia del convenio que someta la controversia entre las partes al procedimiento arbitral, conforme a la ley $\mathrm{y}$ a los reglamentos; $\mathrm{y}$, si fuera preciso, pedirá que el demandante la complete o aclare. No la admitirá a trámite si no se cumplen tales requisitos, o si no se cubre el valor de los costos arbitrales. Una vez que los considere cumplidos, sin pronunciarse sobre su contenido, mandará citar legalmente a la parte demandada, con-

15. Articulo 105 de la Ley Orgánica del Sistema Nacional de Contratación Pública.

16. El Dr. Edgar Neira Orellana lo explica en profundidad en su articulo "La Constitución de 2008 y el arbitraje bajo la ley ecuatoriana: análisis de dos problemas que surgen antes que el texto constitucional, de su equivocada aplicación" publicado en la Revista Ecuatoriana de Arbitraje, año 2011, p. 33.

17. "Curso de Derecho Civil", Arturo Alessandri y Manuel Somarriva, 1992, p. 313. 
forme prescribe el artículo 11 de la LAM. De la misma manera verificará que la contestación a la demanda cumpla los requisitos legales y reglamentarios y, de haber reconvención mandará citarla a la parte contraria. En ambos casos exigirá previamente el pago de los costos establecidos. La omisión de citar en legal forma, genera la nulidad del proceso arbitral conforme al lit. a) del artículo 31 de la misma ley.

Al Centro de Arbitraje le corresponde designar y posesionar a los árbitros en la forma prevista en la ley, en el reglamento interno y en el convenio arbitral, condición esencial para que el Tribunal o el árbitro asuma el conocimiento y decisión del juicio arbitral. Si las partes han establecido la forma cómo designar a los árbitros, se procederá en consecuencia. De otra forma, el Director del Centro les pedirá ponerse de acuerdo y designarlos de entre los que constan en la Lista Oficial o de fuera de ella. Si las partes no se ponen de acuerdo o se han remitido al Reglamento del Centro, se sortearán de entre los que consten en la lista de dicha entidad. Todo este procedimiento deberá constar en autos.

Posesionado el Tribunal o el árbitro único, la primera decisión que se debe adoptar es la resolución sobre su propia competencia, como manda el Art. 22 de la LAM. Deberá hacerlo en la Audiencia de Sustanciación, motivadamente, explicando la pertinencia de su decisión, sobre la base de la ley y del convenio. La consecuencia de no ajustar tal decisión a la ley, acarrea la nulidad. El laudo debe dejar en evidencia el cumplimiento de esta actuación conforme a la ley.

\section{La deCisión SOBRE LA COMPETENCIA DEL TRIBUNAL, ¿PODRÁ SER REVISAdA POR El MISMO TRIBUNAL AR- BITRAL, DESPUÉS DE QUE LA ASUMIÓ?}

La respuesta es negativa porque es una decisión que la ley impone tomar ab initio del proceso, en la Audiencia de Sustanciación, y que causa ejecutoria una vez adoptada. Desde luego, esto 
ocurrirá a menos que sea impugnada, dentro del término de tres días, por cualquiera de las partes ${ }^{18}$, mediante petición de revocatoria o de reconsideración, que deberá resolver el Tribunal o árbitro único antes de dar inicio al proceso arbitral. Si se plantea como excepción, igualmente debe resolverla el Tribunal al momento de decidir sobre su competencia. El laudo deberá dejar constancia del cumplimento de este requisito procesal.

Solamente podría revisarse la decisión sobre la competencia de un Tribunal Arbitral, ya resuelta anteriormente y de acuerdo con la ley, en el evento de que el mismo hubiere encontrado, con posterioridad y durante el proceso, una causa o elemento probatorio que no existió o no pudo analizar al momento de resolver sobre su competencia, como fraude, falsedad o engaño, mediante decisión debidamente motivada, previamente a la expedición del laudo o al expedirlo, sin resolver sobre el motivo de la controversia.

Procesalmente, el juicio arbitral en Derecho se somete a la LAM, desde luego a la jurisprudencia y a la doctrina y, subsidiariamente, al Código de Procedimiento Civil, Código de Comercio u otras leyes conexas, como prescribe el artículo 37 de la LAM. Si es en Equidad, al leal saber y entender de los árbitros, lo que no significa que no se respeten los principios universales del Derecho.

En todo caso, debe cumplirse el trámite previsto en la ley, además de las normas del Reglamento Interno del Centro y, por cierto, las estipulaciones del convenio arbitral, que podría contener algunas de las formalidades del procedimiento arbitral pactadas por las partes, tales como forma de designar el Tribunal; si los Árbitros serían uno o tres; el plazo para duración del Arbitraje; reservas o determinadas hubieran pactado, como forma de designar el Tribunal, o si será árbitro único, el plazo, reservas o determinadas condiciones, como establece el artículo 38 LAM. Obviamente deben observarse los Derechos garantizados por la Constitución y la Ley, en cuanto corresponda.

18. Arts. 281 y 289 del Código de Procedimiento Civil. 
La notificación oportuna y adecuada de las actuaciones del Tribunal arbitral, en el domicilio señalado por cada una de las partes, es elemento sustancial para la validez del procedimiento arbitral; no hacerlo, impide o limita el real ejercicio del Derecho de defensa de alguna de ellas, que puede verse afectado gravemente por la omisión, al igual que incidirá en la decisión arbitral que ponga fin al proceso, por lo que es causa de nulidad.

Lo mismo corresponde a la práctica de pruebas solicitadas por las partes, o dispuestas por el Tribunal en los casos que le permite la ley. La prueba debe ser debidamente pedida y actuada ${ }^{19}$ en los términos que señala la ley y conforme determine el Tribunal. Debe ser pertinente, concretarse al asunto que se litiga y a los hechos controvertidos en el juicio ${ }^{20}$, por lo que el Tribunal o el árbitro están obligados a rechazar la prueba impertinente o inoficiosa. La notificación de la prueba a las partes es elemento esencial para la validez del proceso ${ }^{21}$. Lo es igualmente que la prueba sea una de las admitidas por la ley, pues el artículo 76, numeral 4, de la propia Constitución advierte la nulidad como castigo para la prueba ilegalmente obtenida o actuada.

\section{ACCión de NUlidad del LAUdo ARBITRAL}

Cerrado el silogismo del proceso, debe expedirse el laudo arbitral que contendrá las consideraciones sobre los hechos y sobre el Derecho, y la decisión debidamente motivada del Tribunal, el cual es, por esencia, inapelable. Ciertamente, deberá resolver sobre los puntos de la controversia entre las partes. Debe analizar las posiciones de cada una, valorar la prueba producida y confrontar los hechos alegados con la ley, la jurisprudencia y la doctrina. Dentro de ese marco, no puede dejar de decidir sobre las

19. Art. 117 CPC: "Sólo la prueba debidamente actuada, esto es aqueila que se ha pedido, presentado y practicado de acuerdo con la Ley, hace fe en juicio."

20. Artículo 116 CPC: "Las pruebas deben concretarse al asunto que se litiga y a los hechos sometidos al juicio."

21. Art. 119 CPC: "El jucz, dentro del término respectivo mandari que todas las pruebas presentadas o pedidas en el mismo término, se practiquen previa notificación a la parte contraria." 
pretensiones de las partes, ni resolver más allá de lo que ellas pretendieron.

Como prescriben el artículo 76, ordinal 7, literal 1) de la Constitución, 130, numeral 4, del Código Orgánico de la Función Judicial y 275 y 276 del Código de Procedimiento Civil, normas supletorias de la LAM, el laudo arbitral debe expresar con claridad lo que se resuelve, la motivación comporta la exposición de los antecedentes de hecho confrontándolos con las normas y principios jurídicos en que funda su decisión.

El Tribunal Arbitral, en el evento de encontrar una nulidad procesal conforme al artículo 31 de la LAM, de oficio o a petición de parte, debe declarar la nulidad de lo actuado a partir de la causa que la originó, siempre que la omisión pueda influir en la decisión de la causa, siguiendo las reglas que al efecto prevé el CPC en los artículos 349, 351, 352, 355.

El mismo artículo 31 de la LAM prevé que cualquiera de las partes puede interponer Acción de Nulidad del laudo arbitral. No prescribe que tal acción lo sea del proceso arbitral, porque no significa instancia ni cabe apelación del laudo.

La atribución legal del presidente de la Corte Provincial, competente para conocer y resolver sobre la acción de nulidad del laudo arbitral, está limitada por la ley a examinar la decisión del Tribunal. Deberá verificar si el Tribunal, ha incurrido en alguna de las causas de nulidad del artículo 31 de la LAM, cuando:

a) "No se hayn citado legalmente con la demanda y el juicio se ha seguido y terminado en rebeldín. Será preciso que la falta de citación hnya impedido que el demandado deduzca sus excepciones o haga valer sus Derechos y, además, que el demandado reclame por tal omisión al tiempo de intervenir en la controversia;

b) No se laya notificado a una de las partes con las providencias del Tribunal y este hecho impida o limite el Derecho de defensa de la parte; 
c) Cuando no se hubiere convocado, no se hubiere notificado la convocatoria, o luego de convocada no se hubiere practicado las pruebas, a pesar de la existencia de hechos que deban justificarse;

d) El laudo se refiere a cuestiones no sometidas al arbitraje o conceda más allá de lo reclamado; 0 ,

e) Cuando se hayan violado los procedimientos previstos por esta Ley o por las partes para designar árbitros o constituir el Tribunal arbitral."

El trámite de la acción de nulidad, debe ser presentado ante el propio Tribunal Arbitral, para ante el presidente de la Corte Provincial de la correspondiente jurisdicción, para que sea resuelto en el término de 3 días. Conforme al mismo artículo 31 citado, si la parte accionante pretende suspender los efectos del laudo, deberá rendir la caución suficiente sobre los perjuicios estimados a la otra parte en la demora en la ejecución de laudo.

Rendida la caución, se suspenden tales efectos, si no, el laudo puede ser ejecutado por la parte interesada, para lo cual debe acudir a un juez ordinario de lo civil, y solicitarle que dicte mandamiento de ejecución. No hay más trámite que seguir, se procede como la ejecución de cualquier sentencia ejecutoriada. El juez debe ordenar que el ejecutado pague o dimita bienes en 24 horas. Si no lo hace, dispondrá el embargo de bienes y su consiguiente remate. A menos que fuere preciso liquidar el adeudo mediante perito 22 .

\section{6. ¿Procede aplicar otras causales de nUlidad, COMO LAS QUE ESTABLECE EL ARTículo 355 DEL CPC?}

Mi posición es que no. El artículo 226 de la Constitución de la República preceptúa que el Estado y sus servidores, "...ejercerán solamente las competencias y facultades que les sean atribuidas por la Constitución y la Ley..." Las instituciones del Estado y sus ser-

22. Articulos 438 y $439 \mathrm{del} \mathrm{CPC}$

Revista Ecuatoriana de Arbitraje 
vidores, entre ellos los órganos y los jueces de la Función Judicial, deben limitarse a aplicar la ley. No pueden interpretarla a pretexto de consultar su espíritu, cuando su tenor literal es claro, les está prohibido hacerlo (artículo 18 , regla $1 \mathrm{del} \mathrm{CC}{ }^{23}$ más cuando hay ley expresa y taxativa que establece las causales en la ley especial, la LAM, por lo que no cabe acudir a otras leyes que suplan lo que está prescrito, menos a casos análogos de otras leyes (artículo 18, regla 7 del CC) ${ }^{24}$; solo al legislador le corresponde interpretarla ley de manera generalmente obligatoria, como prevén el artículo 120, ordinal 6, de la Constitución de la República ${ }^{25}$, y el artículo 3 del Código Civil ${ }^{26}$.

El artículo 37 de la $\mathrm{LAM}^{27}$ se remite a las normas del CPC, como supletorias, es decir que substituyen la falta de alguna norma expresa en la LAM, por lo que las causales taxativas, expresamente previstas en el artículo 31 de la LAM, son las únicas que procede aplicar, no es procedente añadir otras, o substituirlas por otras, en interpretación extensiva, cuando ya constan prescritas en la LAM.

El presidente o la Sala de la Corte Provincial, en su caso, deben concretarse a examinar en el laudo, la existencia de una o varias de las causales del artículo 31 de la LAM, invocadas por el accionante y a declarar consecuentemente la nulidad del laudo arbitral o a desestimar la acción, según corresponda.

La Acción de Nulidad, insistimos, NO CONSTITUYE APELACIÓN NI INSTANCIA, por lo que no es procedente que los

23. Código Civil, Articulo 18 "Los jueces no pueden suspender ni denegar la administración de justicia por oscuridad o falta de ley. En tales casos juzgarán atendiendo a las reglas siguientes: - "la.- Cuando el sentido de la ley es claro, no se desalenderá su tenor literal, a pretexto de consultar su espiritu."

24. "7a.- A falta de ley, se aplicarín las que existan sobre casos análogos; y no habiéndolas, se ocurrira a los principios del Derecho universal."

25. CPR. Articulo 120: "La Asambiea Nacional tendrá las siguientes atribuciones y deberes, ademús de las que determine la ley: - "6. Expedir, codificar, reformar y derogar las leyes, e interpretarlas con carácter generalmente obligatorio."

26. CC, Articulo 3: "Sólo al legislador toca explicar o interpretar la ley de un modo generalmente obligatorio."

27. LAM, Articulo 37: "En todo lo que no esté previsto en esta ley, se aplicarán supletoriamente las normas del Código Civil, Código de Procedimiento Civil o Código de Comercio y otras leyes conexas, siempre que se trate, de arbitraje en Derecho." 
jueces ordinarios analicen el contenido del proceso arbitral, y modifiquen como consecuencia su contenido resolutivo. Les corresponde puntualmente examinar y resolver sobre la existencia de la causa de nulidad invocada por el accionante.

En varias sentencias de la Presidencia de la Corte Superior se ha examinado la interioridad del proceso, bajo el argumento de que el artículo 37 de la LAM, al tratar de "normas supletorias", dicho Juez puede examinar el proceso en su interioridad y aplicar todas las normas que respecto de la nulidad contienen otras normas adjetivas, no obstante que en varias sentencias, la Justicia Ordinaria ha establecido que la Acción de Nulidad "...es un mecanismo de control judicial del procedimiento arbitral mas no vín para acceder a una instancia que revise integralmente la controversia resuelta por el laudo, por lo que las causales para acudir a la acción de nulidad son restrictivas si se las compara con las cuestiones que podrian ser planteadas mediante un recurso de apelación, o cualquiera otra vía que habilite al juez para conocer el fondo de la controversia, por ello se considera como una limitación que impide al juzgador entrar a revisar el fondo del asunto..." 28

En cuanto al trámite que debe darse a la Acción de Nulidad, la LAM no lo determina de manera expresa. La Corte Constitucional ha resuelto el 5 de mayo del 2009, "...Desechar la declaratoria de inconstitucionalidad como consecuencia de la declaratoria de inaplicabilidad del artículo 59 del Código de Procedimiento Civil, emitida por el ... Presidente de la ex Corte Superior de Justicia de Quito;..." por lo que, según esta resolución, el trámite que debiera darse a la acción de nulidad, es el de juicio ordinario, porque así lo prevé el artículo 59 del CPC, pero contraído al término de treinta días desde que avoque conocimiento el presidente de la Corte Provincial, como dispone el artículo 31 de la LAM.

28. Sentencia del Presidente de la Corte Provincial No. 97.009 de 9 de abril del 2010, cit. Sentencia No. 04-2012 del mismo Juez. 


\section{7. ¿Por QUÉ INTERVIENe el Estado, a tRaVÉS de las Cortes Provinciales, como contralor legal de LOS LAUDOS ARBITRALES?}

El Dr. Ernesto Salcedo Verduga en su obra "El Arbitraje - la Justicia Alternativa"; dice: "En definitiva pienso que debe observarse y analizarse el sistema arbitral ecuatoriano desde una perspectiva que, aún reconociendo su naturaleza eminentemente procesal, no soslaye o menoscabe sus complejas caracteristicas de institución que, si bien es convencional, en su origen, tiene como propósito esencial y público el de administrar una justicia efectiva y sin dilaciones, satisfaciendo de esta manera el interés individual que busca tal seguridad juridica y al mismo tiempo, el interés de la sociedad al garantizar a ésta que el proceso arbitral es un medio idóneo para conseguir la efectiva tutela del Derecho; es decir, que nos encontramos ante un sistema cuyos efectos jurídicos tienen un alcance que va más allá de la sola voluntad de las partes y de la simple actividad procesal, y, que por lo mismo, reclama un análisis conjunto de la pluralidad de sus elementos para ubicarlo en el lugar exacto que le corresponde a nuestro ordenamiento legal".

Procede apelación de la decisión del presidente de la Corte Provincial? Según el artículo 76, numeral 7, lit. m) de la vigente Constitución de la República, en todo proceso en el que se determinen Derechos y obligaciones de cualquier orden, se asegura el Derecho al debido proceso que incluirá las siguientes garantías básicas: "7. El Derecho de las personas a la defensa incluirá las siguientes garantias: $m$ ) Recurrir del fallo o resolución en todos los procedimientos en los que se decida sobre sus Derechos." Entonces, si la Constitución, que preceptúa en su artículo 424 que es la norma suprema que prevalece por sobre cualquiera otra del ordenamiento jurídico, permite y garantiza recurrir del fallo sobre la acción de nulidad del laudo arbitral que dicte el presidente de la Corte Provincial, y así se ha procedido. 


\section{8. ¿Cabe el recurso de casación de la sentencia QUe emita la Corte Provincial Respecto de la ACCIÓN DE NULIDAD DE LAUDO ARBITRAL?}

Tal recurso se contrae a las sentencias y autos que pongan fin a los procesos de conocimiento dictados por las cortes superiores y los Tribunales distritales de lo fiscal y de lo contencioso administrativo (artículo 2 Ley de Casación). Si someramente entendiéramos que el juicio ordinario es de conocimiento, podría concluirse que procede tal recurso para la sentencia que resuelva la Acción de Nulidad. Pero tal posición pugna con la naturalezaconsensual y autónoma del arbitraje, que esencialmente busca en la alternativa de este procedimiento, una solución más inmediata y efectiva de la controversia entre las partes que buscan evitar los procedimientos previstos para la justicia ordinaria. La Corte Suprema, hoy Nacional, ha decidido en los dos sentidos, de que siendo juicio de conocimiento, procede el recurso de casación; y como la LAM no prevé tal recurso, resulta improcedente, posición con la cual coincidimos.

Finalmente, declarada la nulidad del laudo arbitral, la consecuencia jurídica es que se repondrá el proceso al estado en que estuvo antes de la declaratoria de nulidad (artículo $355 \mathrm{CPC}$ ). Como se trata de la nulidad del LAUDO arbitral, el proceso deberá reiniciarse, a efecto de lo que el Centro de Arbitraje deberá nombrar nuevos árbitros para que conozcan y resuelvan la causa, sin que por eso pierdan validez las pruebas aportadas durante el proceso (artículo $363 \mathrm{CPC}$ ).

Por todo lo dicho, destacando el valor de la Ley de Arbitraje y Mediación y de su importante aporte a la utilización de los procedimientos de arbitraje y de mediación en el País, concluimosque, actualmente, por la experiencia que hemos logrado acumular, es preciso promover reformas a la ley vigente para que se ajusten los tiempos y a los términos del procedimiento de la acción de nulidad ante la justicia ordinaria, de manera que se delimite la actuación del Estado de constituirse en garante 
del mecanismo arbitral, sin cambiar su naturaleza, y sin que se produzca lo que las partes procesales quisieron evitar, un juicio ordinario con todas las dilaciones y falencias que el arbitraje que han convenido de mutuo acuerdo, busca superar de manera ágil y previsible. 
